\title{
Las logias italianas en Turquía: entre el fortalecimiento de la comunidad italiana y el cosmopolitismo
}

\section{The Italian lodges in Turkey: between the strengthening of the Italian community and cosmopolitanism}

\author{
Emanuela Locci \\ Universidad de Turín, Italia \\ loccimanuela@tiscali.it
}

Recepción: 7 de septiembre de 2017/Aceptación: 20 de noviembre de 2017

doi: https://doi.org/10.15517/rehmlac.v9i2.30729

Palabras clave

Masonería; Italia; Turquía; cosmopolitismo; revolución.

Keywords

Freemasonry; Italy; Turkey; Cosmopolitism; Revolution.

Resumen

El Gran Oriente de Italia ha cruzado a menudo las fronteras italianas para fundar logias en otros países. En este artículo vamos a describir y analizar el alcance y el impacto de la masonería italiana en el Imperio otomano, que se convirtió después de 1923 en la República de Turquía. De gran importancia es la propensión italiana a mezclarse con la población local, para que la comunidad italiana no sea percibida como un cuerpo extraño, sino como un complemento a la sociedad de acogida.

Abstract

The Grand Orient of Italy has often crossed the Italian borders to found lodges in other countries. In this paper we describe and analyse the depth and impact of Italian Freemasonry in the Ottoman Empire, that after 1923 became the Republic of Turkey. What is of the utmost importance is the Italian tendency to mix with the local population to such an extent that the Italian community was not perceived as an alien body but rather as complementary part of the host country.

\section{Introducción}

La masonería ya estaba presente en el Imperio otomano, gracias a los franceses, desde finales del siglo XVIII. La presencia inglesa fue más reciente y se remonta al siglo $\mathrm{XIX}^{1}$. Tanto las logias francesas como las británicas incluyeron en sus membresías a los miembros más importantes de sus comunidades.

\footnotetext{
${ }^{1}$ La primera logia inglesa de la que tenemos ciertas noticias fue la Oriental no. 988, fundada en 1856 y dependiente de la Gran Logia Unida de Inglaterra y, habiendo interrumpido sus actividades en 1949,
} 
Han llegado pocos datos sobre las actividades masónicas europeas en el Imperio otomano durante el siglo XVIII. De hecho, hasta 1804 no se vuelven a tener datos fiables con la constitución de la primera logia extranjera en Alepo, Siria ${ }^{2}$.

La falta de fuentes sobre las primeras logias en territorio otomano se debe también al clima hostil hacia la masonería, determinado por la excomunión papal de Clemente XII en 1738. En 1745, el vicario apostólico de Esmirna, Gerolamo Lanza de Peraino, se encargó de informar sobre ella entre las diferentes comunidades católicas. Los sacerdotes advirtieron a la feligresía del grave pecado que enfrentarían en caso de su afiliación a la masonería. Por último, las autoridades eclesiásticas exigieron la intervención del sultán Mahmud $\mathrm{I}^{3}$ para contrarrestar la expansión de las logias masónicas en Constantinopla ${ }^{4}$. El sultán intervino en 1748 cuando ordenó a la policía que entrara en las logias y detuviera a los masones. La misión policial ordenada por el sultanato no tuvo éxito porque el embajador inglés, masón, pudo avisar a sus hermanos. A pesar de las medidas restrictivas adoptadas por el jerarca, las logias pronto reanudaron sus actividades, aunque con mayor cautela.

\section{La masonería italiana en el Imperio otomano}

La masonería italiana se organizó tanto en la capital otomana, Constantinopla, como en las provincias, como Salónica e Esmirna, localidades con presencia de una numerosa comunidad italiana. Las primeras manifestaciones masónicas italianas se remontan a 1862 con la organización de la logia Italia en Constantinopla, dependiente del gran oriente con sede en Turín, que contó con la participación del marqués Camillo Caracciolo di Bella, embajador del Reino de Italia en la Puerta Sublime. El reciente hallazgo de la lista de miembros en 1864 arroja una nueva luz sobre la historia de esta logia ${ }^{5}$. Este documento permite comprender el tamaño y el número de masones de la logia Italia. Del estudio de los nombres se identifica la participación de italianos, judíos, griegos y armenios. La asociación de otomanos llegó en los años siguientes. En la composición social de la logia se observa el principio de universalidad de la masonería y su apertura a los hombres pertenecientes a diferentes religiones y grupos étnicos. Dos años después de su fundación, según este documento, esta logia contó con setenta masones activos y nueve candidatos a

representó uno de los centros de acción de más larga vida de la historia de la masonería del Imperio otomano. Emanuela Locci, "The First English Lodge in the Ottoman Empire: Oriental Lodge, 1856-1909", en Reflections on 300 years of Freemasonry, ed. John S. Wade (Londres: ARS, 2017), 411-418.

${ }^{2}$ Esta logia la organizó la Gran Logia de Escocia y la dirigió el cónsul británico Alexander Drummond.

${ }^{3}$ Mahmud I, hijo del sultán Mustafa II, ascendió al trono en 1730 y murió el 13 de diciembre de 1754, tras la oración del viernes. Justin Mccarthy, I Turchi Ottomani, dalle origini al 1923 (Génova: ECIG, 2004).

${ }^{4} \mathrm{El}$ nombre que conocemos hoy, Estambul, se convirtió en el nombre oficial de la ciudad en 1930.

${ }^{5}$ Archivo Histórico del Gran Oriente de Italia, Lista matricolare, 1-2. 
ser asociados. Se supone que en 1864 se inició un mulá turco de renombre ${ }^{6}$, pero sin aportarse más datos sobre esta persona, ni su nombre. Italia operó con frecuencia en colaboración con la Sociedad Obrera de Asistencia Mutua fundada en $1863^{7}$, ya que muchos de sus miembros eran también masones ${ }^{8}$, desarrollándose entonces una red de sociabilidad ampliada. Esta logia terminó sus actividades en 1867 debido a problemas internos. Sin embargo, su valor masónico permanece intacto: entre sus afiliados se encontró Louis Amiable, dignatario del Gran Oriente de Francia en la capital otomana.

Después de la experiencia masónica de la Italia, se identificó en igualdad de importancia la logia Italia Risorta, creada el 10 de marzo de 1869 bajo la jurisdicción del Gran Oriente de Italia en Roma. Su líder fue el gran orador de la disuelta Italia y se eligió como venerable maestro a Antonio Geraci y como secretario a Enrico Ottoni, figuras inminentes de la comunidad italiana.

Italia Risorta, a pesar de algunas dificultades administrativas, debido principalmente a la inestabilidad del Gran Oriente de Italia, pronto se impuso en el ambiente masónico de Constantinopla. Continuó con numerosas obras de caridad apoyadas por el sultán Abdülhamid II, quien en una ocasión participó con la donación de cien liras turcas ${ }^{9}$. La logia italiana funcionó sin interrupción durante todo el reinado de este monarca, en contraposición a las logias francesas que suspendieron sus actividades debido a la oposición sultánica. Esta logia no participó de forma oficial a las iniciativas revolucionarias de inicios del siglo XX, lo que le apartó del peligro de impugnación o prohibición que golpearon a muchas otras logias de la capital. No hay evidencias que demuestren la implicación directa de Italia Risorta en la conspiración de los Jóvenes Turcos, pero iniciativas tales como las fiestas y los banquetes probablemente tuvieron mayores propósitos que los propios de la beneficencia. En esas ocasiones se hizo propaganda masónica y la masonería italiana de Salónica funcionó como la anti-cámara oculta del movimiento de los Jóvenes Turcos ${ }^{10}$.

La inserción de la masonería italiana en la sociedad otomana, en comparación con la de otras masonerías, tuvo resultados bastante modestos: una pequeña membresía y un mínimo de musulmanes interesados en asociarse a ella. Y si bien sus actividades siguieron un curso regular a través de los años, se redujeron durante la década anterior a la revolución

\footnotetext{
${ }^{6}$ El mulás es un maestro de las escuelas primarias islámicas, la base de lo que indebidamente puede ser identificado como el clero islámico. El uso de este término se limita al mundo turco, iraní e indio.

${ }^{7}$ La Sociedad de Asistencia Mutua se organizó en 1863 con cuarenta y un italianos residentes en Constantinopla, entre quienes sobresalieron Carlo Alloli, Paolo Mencacci, Camillo Pellegrini y Luigi Gambara. Adriano Marinovich coord., La Società Italiana di Mutuo Soccorso in Costantinopoli (Estambul: Guzel Sanatlar Matbaasi, 1995).

${ }^{8} \mathrm{La}$ fundación de las sociedades de asistencia mutua se vinculó a la figura de Giuseppe Garibaldi.

${ }^{9}$ Reşat Atabek, "1880-1890 yillari arasinda İstanbul'da dışa masonik faaliyetler", Mimar Sinan 68 (1994): 6.

${ }^{10}$ Thierry Zarcone, Mystiques, Philosophes et Franc-Maçons en Islam (París: I.F.E.A. y Maisonneuve, 1993), 215.
} 
de 1908, la guerra en Libia y la primera guerra mundial. Italia Risorta cerró definitivamente sus trabajos masónicos con el nacimiento de la República de Turquía en 1923.

A pesar de que entre las diferentes masonerías en Constantinopla, la italiana tuvo el menor impacto en su inserción social, fueron precisamente los masones italianos quienes atrajeron al mayor número de reformistas y revolucionarios a su órbita. No es una coincidencia que los movimientos de los Jóvenes Otomanos y de los Jóvenes Turcos tuvieran una estructura interna muy similar al de los carbonarios. Los acontecimientos anteriores a la unificación italiana y el papel de las sociedades secretas en ese contexto, representaron un hito histórico para los otomanos deseosos de liberarse del poder opresivo del sultán Abdul Hamid II. La masonería italiana exportó al Imperio otomano los ideales del Risorgimento y del propio Giuseppe Garibaldi. Muchos de los seguidores de Garibaldi $^{11}$, tras el clima revolucionario de 1848 fueron capturados y exiliados a Constantinopla, como fue el caso del doctor Emilio Cipriani ${ }^{12}$, quien continuó ejerciendo allí su profesión y volvió a Italia en 1859 para participar en la fundación de la Italia unida, regresando a Constantinopla e iniciándose masón en 1878 en la logia Italia Risorta.

\section{La masonería italiana en Salónica}

El mayor crecimiento de la masonería italiana se dio en Salónica, donde se afincó una numerosa colonia italiana. La primera logia se organizó durante la década de $1860^{13}$, pero el verdadero protagonismo del gremio tuvo por protagonista a la logia Macedonia Risorta, organizada en 1902 por el Gran Oriente de Italia. En 1904 se eligió como venerable maestro a Emanuele Carasso ${ }^{14}$, quien ocupó el cargo hasta 1909 cuando se trasladó a Constantinopla para trabajar en el Parlamento otomano, para el cual le eligieron diputado después de la revolución de $1908^{15}$. Esta logia aglutinó a importantes actores en los procesos de cambio del Imperio otomano ${ }^{16}$, individuos procedentes de diversos entornos sociales y heterogéneas nacionalidades ${ }^{17}$.

\footnotetext{
${ }^{11}$ Acerca de su vida puede consultarse la obra de Alfonso Scirocco, Garibaldi, Battaglie, Amori, Ideali di un Cittadino del Mondo (Bari: Editori Laterza, 2001); y Mario White, Garibaldi e i suoi Tempi (Milano: Treves, 1884).

${ }^{12}$ Emilio Cipriani nació en Florencia el 16 de septiembre de 1814. Debido a sus ideas liberales se vio obligado a exiliarse en el Imperio otomano y de regreso a Italia fue nombrado gran maestro adjunto del Gran Oriente de Italia. Fue elegido senador en noviembre de 1881 y murió en Roma el 16 de junio de 1883.

${ }^{13}$ Orhan Koloğlu, L'influsso della massoneria italiana sulla rivoluzione dei Giovani Turchi (Bucarest: Quaderni della Casa Romena, I.C.R., 2006), 132.

${ }^{14}$ Emanuele Carasso, un judío sefardita que se jactó de estrechos vínculos con Italia, se inició en la logia Macedonia Risorta el 20 de mayo de 1902.

${ }^{15}$ Como demuestra el anuario masónico del Gran Oriente de Italia, en 1909 Emanuele Carasso fue venerable de la logia Macedonia Risorta y en el anuario de 1910 el venerable maestro es Moisés Levy.

${ }^{16}$ Selanik’te Kurulan Localar“, Mimar Sinan 130 (2003): 21.

17 "Lista matricolare Loggia Macedonia Risorta", 60.
} 
Entre 1902 y 1908 hubo 188 afiliaciones, veintitrés de las cuales eran de oficiales en servicio de la segunda y la tercera armada del ejército imperial. Esta masiva presencia de militares generó varios desacuerdos, por lo que algunos masones decidieron, en signo de protesta, salir de la logia italiana y unirse a la logia francesa Veritas.

Aunque el sultán no se opuso abiertamente a la masonería italiana, su ascensión al trono llevó a un periodo de inmovilización en las actividades de las logias. Para remediar esta situación, el entonces gran maestro Ernesto Nathan del Gran Oriente de Italia ${ }^{18}$ envió al gran maestro adjunto Ettore Ferrari ${ }^{19}$ en misión al Imperio otomano. El viaje tuvo lugar en septiembre de 1900 y sirvió para sacudir a los masones inactivos de las logias de Constantinopla, Salónica e Esmirna. La vieja logia pronto se reorganizó pero ahora con el nombre de Macedonia Risorta en Rue Boulma Giani. Entre sus nuevos miembros figuraron el comandante de Estado mayor İsmail Hakki Cambulat y el ministro de Justicia Zade Refik Bey, así como el gran visir Mehmet Talat Paşa, el ministro de Interior Mithat Şükrü Bleda y el comerciante Rahmi Ben Riza ${ }^{20}$. Todos ellos con roles importantes en la revolución de 1908, e iniciados masones en 1903, es decir, tres años antes del nacimiento del Comité de Unión y Progreso -solo Cambulat se inició después de la organización del Comité. Esto indica que es muy probable que transfirieran las consideradas nuevas ideas discutidas y debatidas en la logia al Comité.

La masonería italiana, y específicamente Emanuele Carasso, no se quedaron de oídos sordos a la solicitud de auxilio de los Jóvenes Turcos. Los revolucionarios empezaron a reunirse en algunas habitaciones cercanas al templo de la logia Macedonia Risorta, aprovechando el hecho de que los extranjeros y sus bienes estaban resguardados y con garantías por el régimen de capitulaciones ${ }^{21}$. Las otras logias italo-hablantes abrieron las puertas a los Jóvenes Turcos que lo pedían. Por ejemplo, el gran maestro de Ettore

\footnotetext{
${ }^{18}$ Ernesto Nathan nació en Londres en 1845, hijo de descendientes judíos sefarditas, la italiana Sara Levi y el alemán nacionalizado inglés Mayer Moses. Después de la muerte prematura de su padre, Nathan se trasladó a Italia, permaneciendo en Florencia, Milán, y por poco tiempo en Cerdeña, donde administró una fábrica de algodón que después fracasó. En 1867 se casó con Virginia Mieli y tres años más tarde llegó a Roma donde se dedicó a la política con una vocación secular y anticlerical. En 1887 se inició masón y después de nueve años se convirtió en gran maestro del Gran Oriente de Italia, sucediendo a Adriano Lemmi y permaneciendo en el cargo hasta 1903. De 1917 a 1919, después de la renuncia de Ettore Ferrari, volvió a cubrir esta posición. En su carrera política, después de numerosas asignaciones como concejal, en 1907 fue elegido alcalde de Roma (el primero que no pertenecía a la clase de los terratenientes) y mantuvo el cargo hasta 1913. Murió en Roma en 1921.

${ }^{19}$ Ettore Passalalpi Ferrari, Ettore Ferrari, tra le muse e la politica (Perugia: Edimond, 1995), 274.

20 "Lista matricolare Loggia Macedonia Risorta", 59-60.

${ }^{21}$ El régimen de las capitulaciones se componía de un conjunto de convenciones y de garantías internacionales otorgadas a las potencias europeas por parte del Imperio otomano, para regular la posición de los extranjeros que vivían en los territorios imperiales. Los extranjeros estaban sujetos a las leyes de su país de origen, y las consecuencias adicionales se referían a los derechos de aduana que se habían eliminado por completo. Las capitulaciones dejaron de producir sus efectos en 1914.
} 
Ferrari $^{22}$, apoyó abiertamente en nombre de todos los masones italianos la revolución turca de 1908 y afirmó públicamente que algunos importantes dirigentes del Comité de Unión y Progreso estaban vinculados al Gran Oriente de Italia. Ferrari durante una conferencia en Génova, en la logia Goffredo Mameli, explicó que la legislación turca prohibía el derecho de asociación a sus ciudadanos ${ }^{23}$, y que durante sus viajes a Occidente, los liberales turcos habían visto los resultados obtenidos por la masonería, decidiendo recurrir a los masones italianos para contrarrestar el autoritarismo del sultán.

La proximidad del movimiento revolucionario a la masonería destacó también por la afinidad entre los rituales de la iniciación masónica y el ingreso de individuos en el movimiento. Los vértices de los Jóvenes Turcos dieron la bienvenida a nuevos activistas con una ceremonia tomada en parte de los rituales masónicos ${ }^{24}$. El candidato se colocaba frente a una delegación del comité ejecutivo del movimiento para ser examinado sobre sus principios políticos y su personalidad. Si el examen tenía éxito, juraba de pie, con la mano derecha extendiéndose a un altar donde había una pistola, pronunciando la frase: "Juro derramar mi sangre hasta la última gota por la libertad, por dar cumplimiento exacto a las órdenes del comité de agitación y perseguir el objetivo del Comité" 25 .

El objetivo del movimiento revolucionario era restaurar la constitución política, suspendida por el sultán poco después de su entrada en vigor. Abdullhamid, gracias a su espesa red de espías, se dio cuenta de que muchos oficiales del ejército se habían convertido a la causa liberal y revolucionaria. Salónica estuvo cerca de ser asediada por el ejército del sultán, quien envió a dos generales armados para desmantelar el movimiento revolucionario y someter a la logia Macedonia Risorta a una estricta vigilancia. En marzo de 1908, la policía entró en la logia, buscando listas de afiliados y otras cartas comprometedoras, pero no pudo encontrar nada útil porque el venerable maestro Emanuele Carasso había sido advertido oportunamente, por lo que quitó todo lo que podría ser considerado comprometedor ${ }^{26}$.

\footnotetext{
${ }^{22}$ Ettore Ferrari, escultor, escritor y pintor, nació en Roma el 25 de marzo de 1845, por Maria Luisa Pasini, descendiente de una noble familia de Florencia, y Filippo Ferrari, un escultor muy valorado. Después de graduarse en letras estudió en la Academia de Arte de San Luca y en 1881 se inició masón en la logia Rienzi de Roma, de la que fue venerable maestro en 1892. En 1896 se convirtió en gran secretario del Gran Oriente de Italia y, como partidario ferviente de Garibaldi, en 1897 organizó la expedición de voluntarios a Creta. Se convirtió en profesor en el Instituto Superior de Bellas Artes y fue elegido diputado por tres mandatos, en 1882, en 1886 y en 1890. En 1900 se convirtió en gran maestro adjunto y el mismo año fue a Turquía, enviado por el gran maestro Ernesto Nathan, para tratar de contrarrestar a los movimientos de reforma. En 1904 se convirtió en gran maestro y permaneció en el cargo hasta 1917 y en 1919 fue nombrado gran maestro honorario. En 1923 fundó la revista de rito escocés Lux y se convirtió en un opositor feroz del fascismo, tanto que los fascistas devastaron su taller artístico en 1926. Murió el 19 de agosto de 1929, y las autoridades prohibieron los funerales públicos.

${ }_{23}$ Acacia, "La Massoneria e la Rivoluzione Turca", 1910, 123.

${ }^{24}$ Acacia, "La Massoneria e la Rivoluzione Turca", 1910, 125.

${ }^{25}$ Traducción propia de Zarcone, Mystiques, Philosophes et Franc-Maçons, 245.

${ }^{26}$ Angelo Iacovella, Gönye ve Hilal (Estambul: Tarih Vakfi, 2005), 41.
} 
Una segunda irrupción de la policía obtuvo los mismos resultados y una noche, durante una sesión plenaria de la logia, un adepto advirtió de la presencia de policías burgueses que esperaban a la salida a los masones para detenerlos. En el interior estaban los miembros más importantes del Comité, como Rahmi bin Riza y Talat. A la salida se mezclaron con la muchedumbre de adeptos, logrando escabullirse entre la muchedumbre y pasando desapercibidos para los agentes imperiales.

En 1908 la acción de la masonería se hizo más estricta y evidente, y Emanuele Carasso junto con Talat se trasladó a Constantinopla: el propósito de la misión era ponerse en contacto con algunos "hombres de culto" importantes para inducirlos a desplegarse con los revolucionarios. La policía otomana observaba día y noche. Carasso fue detenido e interrogado, pero no traicionó a sus compañeros a pesar de que se abriera una investigación ${ }^{27}$. Esta situación de peligro hizo que los masones fuesen más decididos en la necesidad de apresurarse en las acciones hacia un golpe de Estado al sultán. Una sección del movimiento acentuó las actividades propagandísticas, mientras que los oficiales de la segunda y tercera armada organizaron físicamente al ejército.

Un tercer grupo presionó diplomáticamente al sultán y a los ministros para que restauraran la constitución política. La revolución de 1908 se recuerda como una revolución atípica, ya que no se vertió ni una gota de sangre. Aparte de algunas demostraciones militares, que solían atestiguar las fuerzas en el campo, la revolución triunfó de manera pacífica. Esto gracias a la organización minuciosa llevada adelante por la masonería italiana. Con la restauración del régimen constitucional, eligieron a Talat vicepresidente de la Cámara, y a Rahmi y Emanuele Carasso, diputado para el Colegio de Salónica ${ }^{28}$. También gracias a la victoria, para el 31 de diciembre de 1908, la logia Macedonia Risorta llegó a acrecentar su número de asociados con 167 individuos.

\section{La masonería italiana en Esmirna}

La presencia italiana en Esmirna remonta al siglo XVIII, momento en el que los venecianos, incluidos los de las Islas Jónicas, eran más o menos dos mil personas ${ }^{29}$. La migración genovesa es anterior, existen datos desde los siglos XII y XIII, con las familias Reggi, Castelli, Giustiniani, Giudici, De Portu y D’Andria. Los descendientes de esta última familia se encontraban en la ciudad aún en el siglo XX y aparecen en los registros de la logia I'Mille ${ }^{30}$. En la ciudad, el Gran Oriente de Italia fundó varios talleres, entre los

\footnotetext{
${ }^{27}$ Evram Galante, Histoire des juifs de Turquie (Estambul: Isis Press, 1985), vol. 8, 56.

${ }^{28}$ Para ser elegido diputado, era necesaria la ciudadanía otomana que Carasso pidió y obtuvo en 1908. Fue elegido diputado en 1908, 1910 y 1912.

${ }^{29}$ Marie Carmen Smyrnelis, Une Ville Ottomane Plurielle, Smyrne aux XVIII et XIX siècle (Estambul: Isis Press, 2006), 75.

${ }^{30}$ Registri matricolari Loggia I Mille: 3.
} 
cuales el más significativo desde el punto de vista social y del cosmopolitismo fue Orhaniye no. 1993, logia organizada el 28 de marzo de 1868 bajo la égida del Gran Oriente Italiano y reconocida por el Consejo Supremo del Rito Escocés el 5 de agosto del mismo año. La peculiaridad de esta logia reside en el hecho de que los rituales se realizaban enteramente en turco $^{31}$ y que su venerable maestro, contrariamente a la costumbre, era musulmán.

La logia Orhaniye concedió el supremo mallete a Enverî Efendi, director del Departamento de Salud en Esmirna, y quien representó la logia en 1874 durante las obras de la asamblea constituyente de Roma ${ }^{32}$. Los oficiales de esta logia en 1870 eran todos musulmanes, situación que se repitió solo en 1909 con la creación del Gran Oriente Otomano. En 1872, el venerable maestro fue Giorgio Tamajo ${ }^{33}$, quien también la representó en la asamblea constituyente de Florencia a finales de mayo del mismo año. Después de dicha actividad la logia se disolvió por causas desconocidas, pero en 1873 se reconstituyó. Orhaniye realizaba sus actividades en el mismo lugar de reunión que de otras seis logias más, tres italianas y tres inglesas; en 1878, la logia domicilió sus reuniones en la casa del médico italiano Anacleto Cricca ${ }^{34}$.

Además de la ya mencionada I'Mille, fundada en 1911, las logias italianas fueron la Stella Jonia (1864), la Anacleto Cricca (1867), Orhaniye (1868), la Armenak $^{35}$ y la Fénix, estas dos últimas organizadas en 1873.

\section{Conclusión}

La masonería italiana representa en la historia del Imperio otomano un antes y en el de la República Turquía un después. Aunque la presencia italiana se registró tras otras realidades masónicas, como la francesa o la inglesa, fue capaz de insertarse más que otras masonerías extranjeras en la sociedad otomana, convirtiéndose en protagonista de importantes hechos históricos. Su presencia capilar, tanto en las ciudades más importantes como en las provincias del Imperio otomano, ha dado lugar a una mezcla natural entre los miembros de las logias y la población del lugar. Gestada como una manifestación masónica

\footnotetext{
${ }^{31}$ Koray Özalp, Bület Çetiner, Türk Masonluk Tarihi, vol III (Estambul: ASGLT, 1974), 17.

${ }^{32}$ Logge italiane in Turchia (Roma: ASGOI, 2005), 9.

${ }^{33}$ En 1871 Giorgio Tamajo fue elegido soberano gran comendador por el Consejo Supremo del Rito Escocés Antiguo y Aceptado.

${ }^{34}$ Logge italiane in Turchia, 10.

${ }^{35}$ La logia Armenak no. 3408 se organizó según el rito escocés bajo el Gran Oriente de Italia el 18 de febrero de 1870. En 1873 su venerable maestro fue Acop Sivagian y en 1877 se adhirió a la constituyente de Roma. También esta logia desde 1878 se domicilió en la residencia de Anacleto Cricca. La peculiaridad de esta logia estuvo en su composición, una gran mayoría de armenios. Esto indica que la masonería italiana había logrado insertarse en el tejido social otomano, que por su peculiar característica también estaba constituido por un conjunto de minorías étnicas y no musulmanas.
} 
extranjera, a lo largo de los años supo crear una cohesión entre la comunidad italiana establecida en los territorios imperiales otomanos y los pueblos de estos, sin importar si hubo una mayoría musulmana o las numerosas minorías étnicas y religiosas que constituían la sociedad otomana. Esta conmixtión se trasladó a las relaciones familiares, económicas, institucionales y asociativas, como las masónicas. Demostración de ello es la participación activa de las logias masónicas italianas en la organización de la revolución de 1908. Acontecimiento que ayudó a cambiar la cara del Imperio otomano y a desencadenar otros hechos históricos que condujeron a la instauración de la República. La masonería italiana también contribuyó a la formación del Gran Oriente Otomano en 1909, la primera gran logia turca. Las relaciones de este con el Gran Oriente de Italia no fueron interrumpidas, ni siquiera con motivo de la guerra entre italianos y turcos por el control de Tripolitania en 1911. Al contrario, ambas partes pidieron en repetidas ocasiones la paz, reanudando el concepto de cosmopolitismo connaturado a la institución masónica.

\section{Bibliografía}

Atabek, Reşat. “1880-1890 yillari arasinda İstanbul'da dişa masonik faaliyetler”. Mimar Sinan 68 (1994): 6.

Galante, Evram. Histoire des juifs de Turquie. Estambul: Isis Press, 1985.

Iacovella, Angelo. Gönye ve Hilal. Estambul: Tarih Vakfi, 2005.

Koloğlu, Orhan. L'influsso della massoneria italiana sulla rivoluzione dei Giovani Turchi. Bucarest: Quaderni della Casa Romena, I.C.R., 2006.

Locci, Emanuela. "The First English Lodge in the Ottoman Empire: Oriental Lodge, 18561909". En Reflections on Three Hundred Years of Freemasonry. Editado por John S. Wade. Surrey, UK: Lewis Masonic, 2017.

Marinovich, Adriano coord. La Società Italiana di Mutuo Soccorso in Costantinopoli. Estambul: Guzel Sanatlar Matbaasi, 1995.

Mccarthy, Justin. I Turchi Ottomani, dalle origini al 1923. Génova: ECIG, 2004.

Özalp, Koray y Bület Çetiner. Türk Masonluk Tarihi. Estambul: ASGLT, 1974.

Passalalpi Ferrari, Ettore. Ettore Ferrari, tra le muse e la politica. Perugia: Edimond, 1995.

Scirocco, Alfonso. Garibaldi, Battaglie, Amori, Ideali di un Cittadino del Mondo. Bari: Editori Laterza, 2001.

Smyrnelis, Marie Carmen. Une Ville Ottomane Plurielle, Smyrne aux XVIII et XIX siècle. Estambul: Isis Press, 2006.

White, Mario. Garibaldi e i suoi Tempi. Milano: Treves, 1884.

Zarcone, Thierry. Mystiques, Philosophes et Franc-Maçons en Islam. París: I.F.E.A. y Maisonneuve, 1993. 